\title{
Did Hard Work Ever Kill Anyone?
}

\section{Margaret Logan and Heather Mitchell}

In February 2004 the Australian Government released the discussion papers Australia's Demographic Challenges and A More Flexible and Adaptable Retirement Income System, which invited public submissions on proposals to encourage longer working lives. In Australia's Demographic Challenges the Federal Treasurer, Peter Costello, announced policy initiatives aimed at increasing workforce participation to ensure future economic growth. These measures included encouraging people to delay retirement. The paper claimed that 'paid work gives us the opportunity to develop personally, live independently, and interact socially' (Department of the Treasury, 2004b:7).

In the same month the Australian Bureau of Statistics' (ABS) 2004 Year Book was released and it showed that in the past 20 years the average hours worked by employees had increased by three hours per week. The National Occupational Health and Safety Commission reported that the number of stressrelated workers' compensation claims had 'substantially increased' over the past few years (Macken and Priest, 2004). The Government is promoting later retirement but is it possible that longer working lives could be detrimental to our health?

In order to test whether there is any link between retirement age and age at death we have undertaken a study using data from a pension scheme for retired government employees.

\section{Review of Demographic Trends and Policy Issues}

Due to increasing longevity and lower birth rates many countries, including Australia, will face an 'ageing' of the population. Over the next 40 years this could have significant effects on the economy and our standards of living.

Population ageing will mean there are substantially fewer people in the traditional workforce age bracket of 15 to 64 years old, compared to those aged 65 and over. In the Government discussion paper A more flexible and adaptable retirement income system (Department of the Treasury, 2004a:3), it was predicted that by 2043 there will only be 2.5 people of workforce age for every person aged 65 and over, compared to the current level of 5.3 people of workforce age. This reduction in the proportion of tax-paying workers will affect the Government's ability to raise revenue and provide services. Workers taking early retirement will accelerate this decline.

Margaret Logan is the Education Program Manager at a large superannuation fund and a casual lecturer at the School of Economics and Finance, RMIT University and Heather Mitchell is a Senior Lecturer at the School of Economics and Finance, RMIT University. 


\section{Retirement age}

The notion that men should retire at 65 and women at 60 was established in the early 1900 s as part of the eligibility criteria for age pensions. From the $1980 \mathrm{~s}$ public opinion in relation to an actual 'retirement age' shifted in response to demographic, social, economic and cultural changes. As the proportion of older people in the population increased 'grey power' became a political force. There were calls for legislation to counter the 'effects of structural and attitudinal barriers' that impeded the active participation of older people in paid work and other areas (Pfeffer and Green, 1997:279).

Between 1989 and 1996 most Australian states abolished compulsory retirement and outlawed discrimination on the grounds of age. Encel (1997:138) concludes that, 'The effect of this is, in principle, to break or at least weaken the links between ageing, retirement and pensionability which have existed in much the same form for over a century'. Individuals can extend their working lives should they choose to do so.

A government research report (Ingles, 2000:1) argued:

There is no 'right' retirement age, since the diversity of individual circumstances is such that flexibility will need to be the keynote in future policy development. However, it is important to recognise the effects of the retirement income system (in particular the Age Pension age as well as the age of compulsory preservation [of superannuation]) on public perceptions of what age people should retire.

According to figures from the Australian Bureau of Statistics (ABS 2000:2) the majority of Australians currently retire from the workforce (for other than health reasons) between ages 55 (the current superannuation preservation age) and 69.

\section{Retirement age and death}

In Australia's Demographic Challenges (Department of the Treasury, 2004b) the Australian Government announced policy initiatives aimed at providing greater flexibility for older workers, however the initiatives were dubbed 'work till you drop' by the general public (Tingle, 2004a,b; Gottliebsen, 2004; Fraser, 2004; Smith, 2004). As discussed in an Age editorial (March 17, 2004):

Both Labor and the Coalition have reduced the complex area of superannuation to a series of snappy slogans. This is hardly surprising, given that both parties appear keen to make it an election issue. In Peter Costello's mind, 'demography is destiny'... [however] the electorate has a knack of refining and reducing such generalities to slogans of their own. Coalition policy, supported by Labor, that will allow access to superannuation while encouraging older Australians to continue working, has been rather crudely reduced to 'work till you drop'. 
While the Government's initiatives are intended to allow older workers to phase into retirement gradually, the public perception appears to be that they will have no retirement at all.

The Government has now formalised these proposals, issuing regulations allowing people 55 years of age and over to access their superannuation as a regular income stream from 1 July 2005 without having to retire or change employers. A further incentive, a $\$ 500$ Mature Age Worker Tax Offset for people 55 and over is awaiting legislation. For the policies to have any chance of success the Government will need to demonstrate that people can work until later in life and still enjoy a substantial period of retirement.

In order to test whether there is any link between retirement age and age at death we have undertaken a study using data from ComSuper, a pension scheme for retired government employees including public servants, Defence Force members and employees of government agencies. Although not totally representative of the Australian population, the members of ComSuper have come from a wide range of employment categories. Using this data set we will test the hypothesis that retirement age has no effect on lifespan. If we do find an effect, we will determine whether an increased retirement age is associated with an increased or decreased lifespan.

Research involving longevity in retirement has previously been conducted on the ComSuper data at three year intervals by the Department of Finance and Administration (DFA) as part of government costing of the unfunded liabilities of two of the schemes. Their most recent report in 2003 was prepared using data for the three years to 30 June 2002 .

It was noted in the 2003 DFA report that ComSuper members are retiring at later ages than those assumed in the 1999 report, contrary to previous reports, which had shown a trend of early retirement. This trend of early retirement had also been reported for the wider Australian population in ABS data from 1994. The trend appears to have abated and may have been caused, Ingles (2000:16) suggests, by a range of factors which have now dissipated, such as slowing of the pace of economic restructuring after the early 1990s recession.

Analysis in the 2003 DFA report also revealed that the overall rate of mortality for ComSuper pensioners was lower than the rates previously assumed. The overall pattern of mortality of retiring pensioners also differed from the previous assumptions, with lower rates of mortality from ages 60-85 suggesting that retirement longevity has increased at a greater rate than previously anticipated.

The Australian Government Actuary (AGA, 1999) has also observed an improvement in mortality rates for both males and females in the Australian population since the Australian Life Table 1990-92, especially over the middle to older years of life. The Australian Life Table 1995-97 (AGA, 1999:8) reports that:

Males generally showed a greater percentage improvement with death rates falling by between 10 and $20 \%$ over the ages between 45 and 80 , 
with the largest improvement between ages 50 and 65 . Females experienced an almost constant $10 \%$ improvement over the ages of 50 and 65.

The Australian Life Table 2000-02 (AGA, 2004:6-7) also notes that over the five years to 2000-02 'at these middle to older ages, reported mortality has declined quite markedly'. As this increasing longevity is one of the causes of Australia's perceived ageing population problem it has been the focus of government research and modelling for some time.

\section{Superannuation and retirement income policy}

In the 2002-03 Budget the Federal Treasurer, Peter Costello presented the Intergenerational Report (IGR) prepared by the Treasury Retirement and Income Modelling (RIM) Unit. The report highlighted the need for Australia to begin preparations to counter the effects of the ageing population.

Further to the IGR the Treasurer (Department of the Treasury, 2004b), announced policy initiatives aimed at increasing workforce participation. These included measures encouraging people to delay retirement, arguing that 'labour force participation rates are influenced by individual choices and respond to incentives and barriers'. As noted by Kelly and Harding (2004:107), with approximately half the country's 2.7 million 50-64 year olds currently unemployed or not in the workforce, there is scope to increase the participation rates in this group.

The Labour party have also announced their new superannuation policy encouraging individuals to continue working (Superannuation: Setting a Goal) which is designed to assist individuals to achieve ' 65 at 65 ', meaning achievement of a retirement income stream of 65 per cent of pre-retirement salary at age 65 . Early retirement is not part of the policy platform.

Restricting access to superannuation benefits to encourage the delaying of retirement has been part of the agenda of both the major political parties for some time. Unlike most other countries the Australian retirement system allows for full withdrawal of benefits as a cash lump sum, currently at age 55 upon retirement from the workforce (defined as less than 10 hours gainful employment per week). As the current age for access to the Government funded Age Pension is 65 for males and 62.5 for females (increasing to 65 by 2013) there is ample opportunity to expend the superannuation payment and then be eligible for the Age Pension. This is colloquially referred to as 'double dipping'.

Research from the National Centre for Social and Economic Modelling (NATSEM) suggests that about half of those who retire early have little or no superannuation savings remaining by the time they are eligible for the Age Pension (Kelly and Harding, 2004:104).

In 1992 the Labor Government foreshadowed an increase in the preservation age for release of superannuation benefits, as there was concern about the revenue leakage caused by 'double dipping'. A timetable for implementation was released but the measures were not legislated before the Labor Party lost office in 1996. In 
the 1997-98 Federal Budget the new Howard Government announced that it would proceed with the policy to raise the superannuation preservation age from 55 to 60 by 2025 .

In the same Budget the Government announced an increase in the upper age limit for making superannuation contributions from 65 to 70 years of age, and the Deferred Pension Bonus for individuals who continue in the workforce after reaching Age Pension age. These initiatives recognised and encouraged an increasing trend by older Australians to work past the traditional retirement age of 65 (Department of the Treasury, 2001). The upper age limit for making superannuation contributions was further increased to age 75 in the 2002-03 Budget.

Further tightening of access to superannuation benefits occurred with the requirement that all contributions and earnings from 1 July 1999 be classed as preserved benefits. This means that even contributions from after-tax monies cannot be accessed until a specific condition of release is met.

The World Bank and the Organisation for Economic Cooperation and Development (OECD) have argued for discouraging early retirement and raising retirement ages as a means of coping with the fiscal problems caused by ageing populations (Ingles, 2000:1). The solutions proposed by the Australian Government are in line with these recommended strategies. The Government now needs to convince the Australian public that delaying retirement is an appropriate course of action because as concluded in the paper, A more flexible and adaptable retirement income system, to be effective retirement policies must 'have community acceptance'.

\section{Data and Preliminary Analysis}

The data used in this study consists of 49,879 superannuation records of government employees and Defence Forces personnel who retired between 2 July 1988 and 11 February 2004 inclusive. The data was provided through the Commonwealth Government's superannuation scheme administrator, ComSuper. Older records were transferred to a new computer system on 1 July 1988 and so the data could not be readily provided for retirees before then. The data from two small funds was also omitted as it seemed likely that the 'retirement dates' were instead the dates the records were transferred to the new system. The maximum retirement age for members of both these small funds was over 90 years, and as the total number of records was only 258 , the results did not change significantly when these were removed. A further 18 records were deleted because of missing values or because the recorded date of death was on or before the retirement date.

For privacy reasons, only very limited information on each individual was provided. This consisted of the individual's date of birth, the date of retirement and the date of death, where this applied. The only additional information supplied was the individual's gender and the fund to which they belonged. There are retirees from four funds administered by ComSuper in the data set and these are listed in Table 1 below, together with information of numbers of members. 
Table 1: Funds and their Membership

\begin{tabular}{l|ccccc}
\hline Fund & $\begin{array}{c}\text { Old Public } \\
\text { Service }\end{array}$ & $\begin{array}{c}\text { Old Defence } \\
\text { Force }\end{array}$ & $\begin{array}{c}\text { New Public } \\
\text { Service }\end{array}$ & $\begin{array}{c}\text { New Defence } \\
\text { Force }\end{array}$ & Total \\
\hline Identifier & CSS & DF & PSS & MS & \\
Males & 33155 & 612 & 2404 & 730 & 36901 \\
Females & 10958 & 28 & 1975 & 17 & 12978 \\
Alive & 40662 & 592 & 4284 & 723 & 46261 \\
Dead & 3451 & 48 & 95 & 24 & 3618 \\
\hline
\end{tabular}

Source: Calculations based on ComSuper data.

The largest fund by far is CSS (Commonwealth Superannuation Scheme). The CSS was introduced on 1 July 1976 but has been closed to new members since 1 July 1990. All CSS contributors were given the option of transferring to the PSS (Public Service Scheme). The current membership of the CSS covers all Commonwealth employees who were members on 30 June 1990 and who did not transfer to the PSS when it was established on 1 July 1990 (DFA, 2003:10). The DF and MS Funds are the equivalent funds for military personnel to the CSS and PSS respectively.

Only 26 per cent of our sample is female. This is not surprising as we are looking at retirees and the full impact of the relatively recent increase in working women is yet to be felt.

Some 92.7 per cent of the sample was still alive at the time when the sample ended, 11 February 2004. This gives rise to a type of problem known as censoring. While this is doubtless good news for our sample, it means we will not get good estimates if we model the time to death directly. We would expect that the 7.3 per cent of the sample that has died would consist mostly of short-lived people and so our estimates would be biased downwards. Instead we use a technique called 'survival analysis'. To carry out this type of analysis we estimate survival probabilities at each age a death occurs given the proportion of the sample alive at that time. For example at age 54 years and 122 days there are 46,260 sample members still alive and one person who died at that age. The remaining members were censored before they reached 54 years and 122 days; that is they were younger than this on the cut off date of 11 February. This gives an estimated survival probability of 0.99997 . In our analysis we test to see whether retirement age affects these survival probabilities rather than the age at death.

In Table 2 we give summary statistics of the ages of retirement and death, broken down by fund type. All the age-group distributions are highly non-normal and the retirement ages are positively skewed. The two military funds are much smaller than the other two funds. Their retirement age summary statistics are similar to each other, but retirement is earlier on average than the two public service funds. Based on this we will consider combining the two military funds when fitting the models in the following section. 
Table 2: Descriptive Statistics of Ages to Death and Retirement by Fund Type

\begin{tabular}{l|rrrrrrrr}
\hline Fund & \multicolumn{2}{|c}{ CSS } & \multicolumn{2}{c}{ MS } & \multicolumn{2}{c}{ PSS } & \multicolumn{2}{c}{ DF } \\
Age & Retire & Death & Retire & Death & Retire & Death & Retire & Death \\
\hline Mean & 58.98 & 68.66 & 55.58 & 60.77 & 59.07 & 65.19 & 55.44 & 62.36 \\
Median & 58.32 & 68.80 & 55.00 & 60.09 & 58.31 & 65.82 & 55.00 & 62.58 \\
Std Dev & 3.63 & 5.80 & 1.37 & 3.82 & 3.61 & 4.64 & 1.29 & 4.07 \\
Minimum & 54.00 & 54.34 & 54.12 & 55.53 & 54.00 & 55.36 & 54.00 & 55.91 \\
Maximum & 78.41 & 90.05 & 65.01 & 69.66 & 72.20 & 77.64 & 62.03 & 73.38 \\
N & 44113 & 3451 & 747 & 24 & 4379 & 95 & 640 & 48 \\
\hline
\end{tabular}

Source: Calculations based on ComSuper data.

Table 3 below shows the same summary statistics broken down by gender. Comparing the means of the age at death we see that the males seem to be older at death than the females. Tests of significance using the t-statistic show this difference to be statistically significant at any reasonable level of significance $(t$ stat $=5.08$, p-value $=0.000$ ). This is not what we would expect and is almost certainly caused by the censoring of the data. This could happen if most of the long-lived women are still alive and those who have died were of a relatively young age causing the sample mean age to be smaller than the actual. The proportion of males who have died is 8.4 per cent, while only 4.8 per cent of the females have. This difference again is highly statistically significant $(\mathrm{z}$ value $=$ 608 , p-value $=0.000)$.

Table 3: Descriptive Statistics of Ages to Death and Retirement by Gender

\begin{tabular}{l|rrrrrr}
\hline \multirow{2}{*}{ Age } & \multicolumn{2}{|c}{ Males } & \multicolumn{2}{c}{ Females } & \multicolumn{2}{c}{ Total } \\
& Retire & Death & Retire & Death & Retire & Death \\
\hline Mean & 58.90 & 68.58 & 58.86 & 67.71 & 58.89 & 68.43 \\
Median & 58.15 & 68.73 & 58.21 & 67.41 & 58.17 & 68.51 \\
Std Dev & 3.66 & 5.82 & 3.56 & 5.92 & 3.63 & 5.85 \\
Minimum & 54.00 & 54.34 & 54.00 & 55.13 & 54.00 & 54.34 \\
Maximum & 78.41 & 90.05 & 77.63 & 89.26 & 78.41 & 90.05 \\
$\boldsymbol{N}$ & 36901 & 3017 & 12978 & 601 & 49879 & 3618 \\
\hline
\end{tabular}

Source: Calculations based on ComSuper data. 


\section{Survival Analysis}

When analysing survival times the survival function, $S(y)$, is used. This is defined as the probability that the individual survives for a time greater than $y$, or $S(y)=1$ $F(Y)$, where $F$ is the cumulative distribution function of the lifetime, $Y$. A second closely related function is called the hazard rate function. This is defined as the instantaneous rate (probability) of death given that the individual has survived to time $y$ and is related to the survival function by $h(y)=\frac{f(y)}{S(y)}$, where $f(y)$ is the probability density function.

A commonly used method for survival analysis is called Cox's Proportional Hazards Model (Cox 1972). This was used for example by the Canadian Department of Finance (Compton 2002) to determine factors influencing retirement age and by the FAA Office of Aerospace Medicine (Besco et al, 1995) to determine if airline pilots had a shorter lifespan. This model assumes a proportional relationship between the specific-individual hazard rates and the hazard rate of the relevant population - the so-called baseline hazard function. This ratio is a function of the independent variables, $Z_{i}(y)$ and is given by $\frac{h(y)}{h(0)}=g\left(Z_{i}(y)\right)=\exp \left(\beta^{\prime} Z_{i}(y)\right)$, where $h(0)$ is the baseline hazard function. One of the reasons this model is popular is that there is a direct relationship between the size of the coefficients and the change in the risk. The exponential of the coefficient gives the proportional change in risk for a one-unit increase in the variable.

The assumption of a proportional relationship between the hazard rates can be checked using graphical techniques. This requires estimation of an empirical survival function, which can be found for censored data using the product limit estimator developed by Kaplan and Meier (1958). The data were divided into four approximately equal sets based on the retirement age; $<52.2,52.2$ to $<58.2,58.2$ to $<61.6$ and $\geq 61.6$. A separate survival function was then estimated for each subset. If the proportional hazards assumption holds, plots of $\ln (-\ln (\hat{S}(y)))$ versus survival age should form a set of parallel straight lines. This plot showed the lines were neither straight nor parallel (see Figure 1), indicating that the proportional hazards model is not appropriate.

A more flexible model is based on the Weibull distribution. This allows the hazard rate to be increasing, decreasing or constant; however the estimated coefficients no longer give a direct indication of the size of the change in risk. All that can be said is that a negative coefficient decreases survival and a positive value increases survival, or decreases risk. This model is frequently used when the proportional hazards assumption cannot be applied. For example Olivieri and Pitacco (2002) use this to assist in determining premiums for sickness insurance in retirees and Hamermesh (1985) uses it in modelling economic choices in retirement. 


\section{Figure 1: Proportional Hazards Plot}

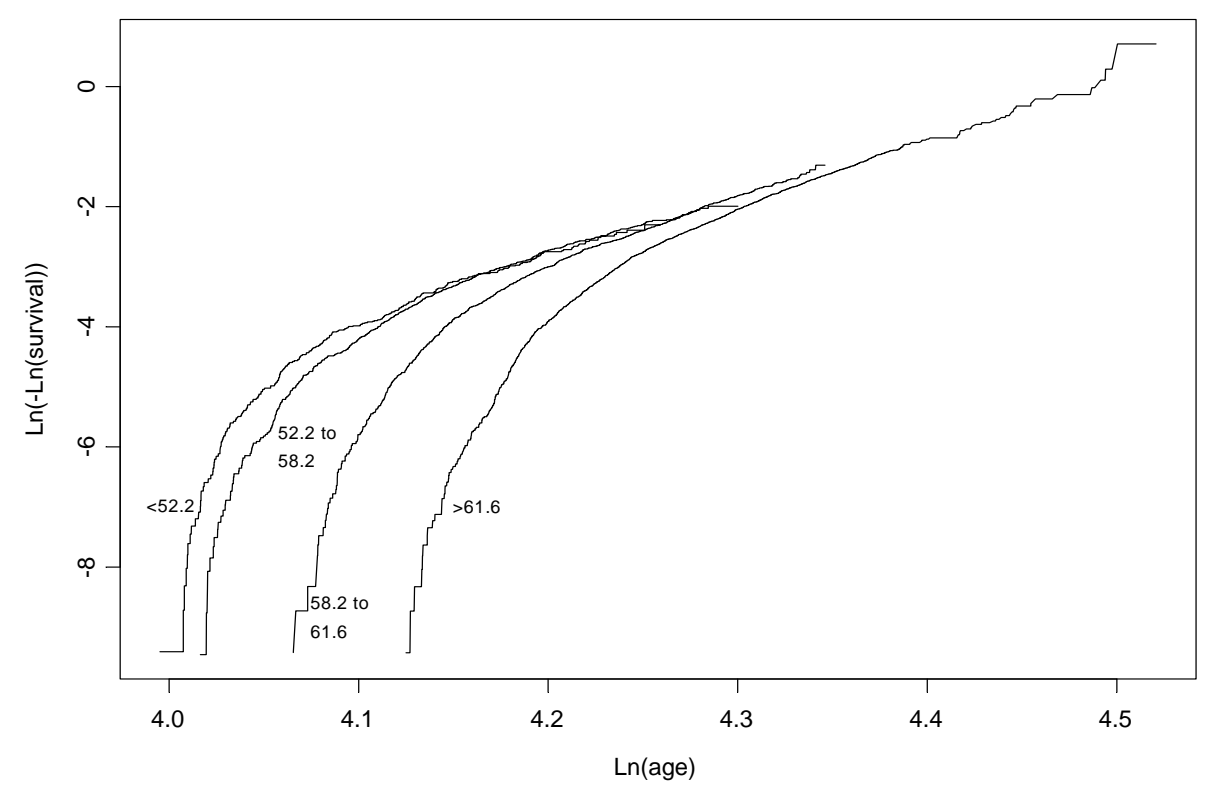

Source: Product limit estimates of survival probabilities based on ComSuper data using Splus.

When lifetimes are assumed to have a Weibull distribution the survival probabilities depend on a linear function of a set of explanatory variables. By estimating the model for these probabilities we can determine which of our variables effect survival and whether they increase or decrease the probability of survival. This distribution also includes a parameter $\alpha$, which determines how the hazard rate behaves. For values less than one it is decreasing, for greater that one it increases and is constant if $\alpha$ equals one. For this data set we expect the hazard rate to increase as risk of death increases with age.

In our first case we model the probability of surviving to a given age (the 'age at death' model) using the explanatory variables:

AgR: age at retirement,

$\mathrm{AgR}^{2}$ : this quadratic term is included to allow for nonlinear effects of retirement age,

LE: life expectancy at retirement,

Male: dummy variable, which is one for males and zero for females,

PSS: a zero one dummy variable for the PSS fund and

DF and MS: defined similarly to PSS. 
Data for life expectancies were obtained from the Australian Life Tables 1995-97 (1999) produced by the Australian Government Actuary. We take the life table for the person's year or retirement, or if that is not available we use the table immediately before the person retired. Using the person's age at retirement and gender we then obtain their expected years of remaining life from the table. The results of this analysis are given below ( $p$-values in parenthesis).

$$
\begin{aligned}
& \ln \left(g\left(Z_{i}\right)\right)=3.94+0.0151 \mathrm{Ag} R_{i}-0.000068 \mathrm{AgR}_{i}^{2}-0.00199 L E_{i} \\
& \begin{array}{llll}
(0.000) & (0.033) \quad(0.244) \quad(0.315)
\end{array} \\
& -0.0366 \text { Male }_{i}+0.175 \text { PSS }_{i}-0.00852 \mathrm{MS}_{i}-0.0132 \mathrm{DF}_{i} ; \quad \alpha=14.95 \\
& \begin{array}{llll}
(0.000) & (0.014) & (0.539) & (0.185)
\end{array}
\end{aligned}
$$

The results give a negative sign on the Male dummy variable, indicating that being male does increase the risk of dying in a given period. Retirement age shows a positive effect indicating that increasing the age at retirement decreases the risk of dying. There is no significant evidence of a nonlinear relationship with retirement age, as the quadratic term is not significantly different from zero. There is evidence that members of the PSS fund have a lower risk of death, but it is hard to explain why being in a different fund increases lifespan. It may be that this is a proxy for life expectancy as it is a newer fund, however when we removed it from the equation the life expectancy variable did not become significant. Being in either of the Defence Force funds had no significant effect on survival. As a check on this result we combined the members of these two funds, but the combined fund still had no significant effect. Surprisingly, life expectancy at retirement does not appear to be significant.

The likelihood ratio test on the whole model gives a highly significant result; 418 which is distributed as $\chi_{(7)}^{2}$ with a p-value of 0.000 . Calculating an exact $\mathrm{R}^{2}$ for this type of model is not possible, but looking at the differences between the fitted age and the actual age for the dead subjects, we find 6 per cent of the total variation is explained. This is not a large amount, but considering we do not have any information on major risk factors other than gender it is not surprising. Plots of the residuals showed no major problems with the model specification. To test whether the small percentage of deaths was likely to cause problems, we estimated the model using only data up until the end of 1990 (9308 data points). This gave a death rate of 20.5 per cent. There were no significant changes in the signs, sizes or statistical significance of the coefficients. We also fitted separate models for males and females. Estimating separate models for males and females allows all coefficients to vary instead of just the intercept, as in the original equation. Again there were no significant changes in the signs, sizes or statistical significance of the coefficients and a likelihood ratio test comparing the single model with separate models for each gender had a p-value of 0.878 .

This model shows a tendency for people who retire early to die early. Is this caused by the stress of social isolation, as discussed in Bunker et al. (2003), or could this be purely an effect of people retiring early because of ill health? In an 
attempt to address this question we fitted a second model. In this we use the survival distribution function, but instead of calculating the probabilities based on age of death, the dependent variable in this regression is the probability that a retiree will survive a certain number of years past retirement. If isolation stress is the main factor we would expect the effect of the age of retirement to decrease considerably. If early retirement because of ill health is the case, we would expect the age at retirement to remain highly significant. Instead of using total life expectancy (LE), we use expected remaining life after retirement (ERL). This is calculated by subtracting the retirement age from the life expectancy.

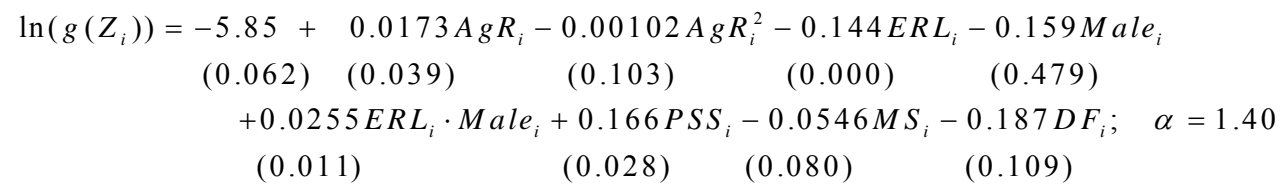

These results show that retirement age is still significant, which supports the hypothesis that people in poor health tend to retire earlier. An extra interactive variable between male and life expectancy has been included. When the model was fitted without this interactive term the male dummy variable had a positive significant coefficient, contrary to what we expect. The interactive dummy suggests that women do not live as long as men, relative to their life expectancy. This may be because women in full time employment are more highly stressed than those at home. Another reason for this may be that male life expectancy is reduced due to 'the greater hazards associated with some occupations which have traditionally been dominated by men (such as mining)' (AGA, 1999:5). As we are only considering public servants, men in these high risk occupations will be underrepresented, and so the life expectancy of this group of men may well be higher than the average.

We now make some predictions. First we re-estimate the first model using only the significant variables. This gives

$$
\begin{array}{ccc}
\ln \left(g\left(Z_{i}\right)\right)= & 4.8056+0.00637 \text { AgR }_{i}-0.0287 \text { Male }_{i}+0.1686 \text { PSS }_{i}, \alpha=14.841 \\
(0.000) & (0.018) & (0.000)
\end{array}
$$

For the predictions in Table 4 we assume the subject is male and in the CSS fund.

The age at death is steadily increasing with retirement age, but less time is spent in retirement. The choice, for public servants at least, is to retire early for maximum retirement length, or later for maximum lifespan. 
Table 4: Estimated age at death and survival probabilities

\begin{tabular}{l|ccccccccc}
\hline Retire & \multicolumn{3}{|c}{ Estimated Life } & Retirement & \multicolumn{4}{c}{ Probability of survival Past Age } \\
Age & Age & S.E. & Length & $\mathbf{6 0}$ & $\mathbf{6 5}$ & $\mathbf{7 0}$ & $\mathbf{7 5}$ & $\mathbf{8 0}$ & $\mathbf{8 5}$ \\
\hline 54 & 81.66 & 0.38 & 27.66 & .989 & .967 & .903 & .754 & .478 & .163 \\
56 & 82.70 & 0.35 & 26.77 & .991 & .972 & .919 & .891 & .547 & .223 \\
58 & 83.76 & 0.32 & 25.76 & .993 & .977 & .933 & .824 & .603 & .289 \\
60 & 84.84 & 0.30 & 24.84 & & .981 & .944 & .852 & .658 & .358 \\
62 & 85.93 & 0.29 & 23.93 & & .984 & .953 & .876 & .707 & .437 \\
64 & 87.03 & 0.29 & 23.03 & & .987 & .961 & .896 & .751 & .494 \\
66 & 88.14 & 0.30 & 22.14 & & & .968 & .913 & .789 & .558 \\
68 & 89.27 & 0.33 & 21.27 & & & .974 & .927 & .822 & .617 \\
\hline
\end{tabular}

Source: Calculations based on ComSuper data using Splus. Predictions are based on the model for age at death using only the significant variables. They are calculated for a male member of the CSS fund.

\section{Discussion and Conclusions}

We have found that retirement age does have an effect on life span. People who retire later live longer. This decreased risk of dying is not large enough to compensate for the extra time spent working, so that those who work longer will spend less time, on average, in retirement.

A finding incidental to the main research was that there were no significant differences between those people in civilian funds and those in Defence Force ones.

As expected our model shows that males are at an increased risk of dying when we consider age at death. Our model for survival past retirement shows that males have a decreased risk compared to females relative to their life expectancy. This may be because the public service does not include the high risk occupations which reduce male life expectancy. It is also likely that the females in the sample are not typical of their contemporaries, being 'career women' at a time when this was not usual. A more detailed data set would be required to determine the most likely cause.

Encouraging older workers to remain longer in the workforce is one of the strategies recommended by the World Bank and OECD for coping with the fiscal problems caused by ageing populations. The Australian Government is also encouraging later retirement, arguing that greater workforce participation will help Australia's future economic growth.

While our results show that working longer appears to be related to an increase in lifespan, the Government may find it difficult to convince the Australian public that delaying retirement is an appropriate course of action. As 
the Government itself has acknowledged, to be effective retirement policies must have community acceptance. More policies that reward later retirement, such as the Mature Age Worker Tax Offset, may be needed.

\section{References}

Australian Bureau of Statistics (1994), 'Australian Social Trends 1994: Early Retirement Among Men', Australia Now, Canberra.

Australian Bureau of Statistics (2000), 'Australian Social Trends 2000: Work - Not in the Labour Force: Retirement and Retirement Intentions', Australia Now, Canberra.

Australian Bureau of Statistics (2004), 2004 Year Book: Labour: Employed Persons (available at www.abs.gov.au).

Australian Government Actuary (1999), Australian Life Tables 1995-97, Australian Prudential Regulation Authority, Australia.

Australian Government Actuary (2004), Australian Life Tables 2000-02, Commonwealth of Australia.

Australian Labor Party (2004), Superannuation: Setting a Goal, March 15. http//:www.alp.org.au, accessed 15 March 2004

Besco, R., S. Sangal, T. Nesthus and S. Veronneau (1995), 'Longevity and Survival Analysis for a Cohort of Retired Airline Pilots', FAA Office of Aerospace Medicine, Civil Aerospace Medical Institute, Aviation Medicine Reports DOT/FAA/AM 95/5, Washington, DC.

Bunker, S., D. Colquhoun, M. Esler, I. Hickie, D. Hunt, V. Jelinek, B. Oldenburg, H. Peach, D. Ruth, C. Tennant and A. Tonkin (2003), 'Stress and Coronary Heart Disease: Psychosocial Risk Factors, National Heart Foundation of Australia Position Statement Update', Medical Journal of Australia 178(17 March):272-276.

Commonwealth of Australia, Appropriation Bill (No. 1) 1997-98, May 13, 1997.

Commonwealth of Australia, Appropriation Bill (No. 1) 2002-03, May 14, 2002.

Compton, J. (2002), 'Determinants of Retirement: Does Money Really Matter?', Department of Finance Working Paper, Canada.

Cox, D. (1972), 'Regression Models and Life-Tables', Journal of the Royal Statistical Society 34(2):187-220

Department of Finance and Administration (2003), PSS and CSS, Long Term Cost Report: A Report on the Long Term Cost of the Public Sector Superannuation Scheme and the Commonwealth Superannuation Scheme 2002, Mercer Human Resource Consulting Pty Ltd, Sydney.

Department of Treasury (2001), 'Towards Higher Retirement Incomes for Australians: A History of the Australian Retirement Income System Since Federation', Economic Roundup Centenary Edition, Australian Government Publishing Service, Canberra, 14 May. 
Department of Treasury (2004a), A More Flexible and Adaptable Retirement Income System, Discussion Paper, 25 February.

Department of Treasury (2004b), Australia's Demographic Challenges, Discussion Paper, 25 February.

Encel, S. (1997), 'Work in Later Life', pp. 138-156 in A. Borowski, S. Encel and E. Ozanne (eds), Ageing and Social Policy in Australia, Cambridge University Press, Melbourne.

Fraser, A. (2004), 'Government Moves to Quell Notion of "work till you drop", ', The Canberra Times (24 March):8.

Gottliebsen, R. (2004), 'Latham Misses Free Kick Chances', The Australian (19 March):17.

Hamermesh, D. (1985), 'Expectations, Life Expectancy and Economic Behaviour', Quarterly Journal of Economics, 100(2):389-408.

Ingles, D. (2000), Structural Ageing, Labour Market Adjustment and the Tax Transfer System, Commonwealth of Australia, Department of Family and Community Services Policy Research Paper No. 5, May.

Kaplan, E. and P. Meier (1958), 'Nonparametric Estimation from Incomplete Observations', Journal of the American Statistical Association 53(262):457-481.

Kelly, S. and A. Harding (2004), 'Funding the Retirement of the Baby Boomers', Agenda 11(2):99-112.

Macken, D. and M. Priest (2004), 'Young and free? Try Tired and Miserable', Weekend Australian Financial Review (28-29 February):6.

Olivieri, A. and E. Pitacco (2002), 'Premium Systems for Post-retirement Sickness Covers', Belgian Actuarial Bulletin 2(1):15-25.

Pfeffer, M. and D. Green (1997), 'The Making of Policies for the Aged', pp. 276-300 in A. Borowski, S. Encel and E. Ozanne (eds), Ageing and Social Policy in Australia, Cambridge University Press, Melbourne.

Smith, P. (2004), 'Costello's Solution Doesn't Go Far Enough', The Sydney Morning Herald (29 February):3.

Tingle, L (2004a), 'Everything Except the Policy Detail', Australian Financial Review (16 March):8.

Tingle, L (2004b), 'Labor's Super Deal is Light on Detail', The Age, News; Leaders, (17 March):14.

The authors wish to thank Noel Cock and Richard Condon of ComSuper for the provision of the data that made this study possible. We also wish to thank the two anonymous referees whose suggestions have improved this paper. 